\title{
Economic Impact of COVID-19 on China: A Comparative Analysis of SARS
}

\author{
Xirui Chen ${ }^{1}$ \\ ${ }^{1}$ The Affiliated High School to Hangzhou Normal University, No.5, Zhenhua Road Hangzhou, Zhejiang 310000, \\ China \\ *Corresponding author. Email: 13666606185@163.com
}

\begin{abstract}
The COVID-19 outbreak in China at the beginning of 2020 not only threatens people's lives and disrupts normal social order, but also brings a great impact to China's economy. As an emergency public health event, the economic environment of COVID-19 has changed greatly compared with the SARS epidemic in 2003. It is of great theoretical significance and practical value to explore the impact of the COVID-19 epidemic on the economy. By comparing and analyzing the specific national conditions, international background and development stage of the SARS epidemic in 2003 and the COVID-19 epidemic in 2020, this paper explores the respective impacts of the two epidemics on various industries of the economy. The results show that the two epidemics have different impacts on various industries of economy. In order to properly deal with the economic crisis caused by the epidemic, we must adopt targeted policies based on the specific background and national conditions of the outbreak.
\end{abstract}

Keywords: Economy, Epidemic, COVID-19, SARS

\section{INTRODUCTION}

Since the 20th century, public health events have occurred from time to time around the world, such as the pandemic influenza in 1918, the SARS epidemic in 2003, the H1N1 influenza in 2009, the Ebola epidemic in 2014, and the new crown pneumonia epidemic in 2020. Such public health incidents seriously threaten the lives of people around the world and affect the social and economic operations of all countries. Among them, the "SARS" epidemic in 2003 and the new crown pneumonia epidemic in 2020 have had a great negative impact on China's macro economy, increasing the uncertainty of economic operations.

SARS broke out in January 2003 and lasted until June, and its economic impact was quite obvious. According to data from the National Bureau of Statistics of China, during the "SARS" period in 2003, the growth rate of China's GDP slowed down significantly, down by about $2 \%$. In the most severely affected areas-Beijing and Guangdong Province, gdp dropped by about $3 \%$ and $1 \%$, respectively. However, due to China's effective epidemic prevention measures and economic recovery policies, with the end of the epidemic, the economies of various regions have gradually returned to normal. Based on annual data, the impact of SARS on China's economy in
2003 was only about $0.5 \%$. From the perspective of the three industries, the SARS epidemic has the most severe impact on the service industry. Although the growth rates of the three industries have all declined, the recovery time of the growth rate of the secondary industry took only 3 months, while the recovery time of the growth rate of the tertiary industry was as long as 6 months.

Based on the experience of the SARS epidemic on the overall economic impact, this article can make a preliminary prediction: on the one hand, the new crown pneumonia epidemic will also have an impact on the economy, but under effective prevention and control measures and economic recovery policies, the economy will gradually recover. On the other hand, from 2003 to 2019, the proportion of China's tertiary industry's GDP has gradually expanded, rising from $42 \%$ in 2003 to $54 \%$ in 2019. Since the tertiary industry already accounts for half of China's economy, it will be most affected by the new crown pneumonia epidemic compared to other industries.

From the perspective of the epidemic itself, SARS and COVID-19 have the following common points: First, both outbreaks occurred in December. The SARS epidemic appeared in early December 2002, and the first case of COVID-19 patient in Wuhan came down on 
December 8, 2019. Second, the government has attached great importance to the epidemic. In response to the two epidemics, the government held frequent meetings to study the situation and prevention and control measures. Third, there is human-to-human transmission in all cases, and the geographical distribution of cases is wide. Under the SARS epidemic, 25 regions in China have confirmed cases, and COVID-19 cases have covered all regions of the country. Fourth, WHO has responded to all outbreaks. WHO issued a global alert for SARS on March 12, 2003, and declared COVID-19 as "Public Health Emergencyof International Concern (PHEIC)" on January 31, 2020.

However, the current COVID-19 epidemic is very different from the SARS epidemic. First, the SARS epidemic in 2003 was controlled to a high degree, the disease did not spread nationwide, and the economic affected areas were only located in the most severely affected areas of the SARS epidemic.Instead, COVID-19 swept across the country, causing economic stagnation across the country. Second, the number of people diagnosed with COVID-19 has far exceeded that of SARS, and the impact of the rapid decline in the number of labor force on China's economy and society has far exceeded that of SARS.

In addition, the circumstances of the two outbreaks are different. First, there are significant differences in the stages of economic development. In 2003, China was in the period of rapid economic growth, but at present, China's economic growth has dropped from high speed to medium to high speed, and is still in the stage of bottoming out. The economic structure and consumption structure have undergone profound changes. Second, there are differences in the uncertainties of China's external environment. In 2003, China was in the period of economic take-off after joining the WTO, enjoying the "globalization dividend". At present, the economic and trade frictions between China and the United States are not resolved, economic turbulence is inevitable, the global economy is weak and there is no clear signal of recovery. Third, there are differences in the industrial chain of enterprises. In 2003, Chinese enterprises were still in the stage of rapid growth and the industrial chain was relatively short. The current industrial chain of enterprises is wide and long, and the impact may be more serious.

Therefore, the impact of the SARS epidemic and the new crown pneumonia epidemic on the economy will also be different. This article will study the impact of the two epidemics on Chinese manufacturing industry, catering, hotel and tourism, transportation, logistics, banking, securities industry based on different era backgrounds, specific national conditions and economic environments, try to predict the impact and effect of this new crown pneumonia epidemic on various industries.

\section{LITERATURE REVIEW}

Many scholars have studied the impact of public emergencies on economy. Worthington (2008) pointed out that public emergencies would not only cause direct damage to the affected areas, but also cause supply chain disruption, which would then transfer risks to the originally unaffected areas and cause a large number of direct and indirect economic losses [1]. Goh and Law (2002) investigated the impact of the Asian financial crisis in 1997 and the avian flu epidemic in Hong Kong, China, on the tourism industry through the intervention model, and the study showed that such public events would have a significant negative impact on the tourism industry [2]. Deryugina et al. (2018) compared New Orleans hit by Hurricane Katrina with similarly developed cities in the United States, and investigated the impact of this sudden event on wage income, employment, marriage and childbirth, and found that there was only a temporary negative impact [3]. Through quasi-natural experiments, Boehm et al. (2019) discussed the impact of the "March 11" earthquake in Japan on the international trade industry chain, and found that the overseas upstream and downstream enterprises of Japanese multinational corporations were affected by significant spillover impact [4]. Under the impact of crisis events, there will be obvious risk transmission between financial markets, and risk spillover effect will significantly increase [5]. After being impacted by unexpected events, the stock market may produce "overreaction" phenomenon in the short term, and appear large abnormal shocks [6]. Emergencies will aggravate the fragility of the financial system, resulting in sudden changes in the original correlation between financial institutions or markets after the crisis, thus increasing the difficulty of risk prevention and control [7].

Looking at the research in this field, most of the existing literature examines the macroeconomic impact of natural disasters such as earthquakes and hurricanes, while less discusses the negative impact of major public health events. Major public emergencies such as SARS and COVID-19 pose a serious threat to China's economic stability and social security. In view of this, this paper will make a comparative analysis of the impact of SARS and COVID-19 on China's macro economy based on the economic background and development stage when the epidemic occurred.

\section{ANALYSIS OF INDUSTRIES}

\subsection{Consumer Goods Industry}

In April 2003, the growth rate of total retail sales of consumer goods began to decline and has been in a downward trend. At the end of SARS in June, the total retail sales of consumer goods suddenly reversed and immediately returned to normal levels. Since then, the 
development of social consumption has even greatly exceeded the normal level [8]. It can be reasonably predicted that during the new crown pneumonia epidemic, consumers will reduce their shopping due to anti-epidemic policies such as lockdowns. Consumable industry will be severely impacted, but after the gradual relaxation of the epidemic prevention policy, consumable industry will quickly resume.

However, unlike the SARS period, when the new crown pneumonia epidemic broke out, thanks to the rapid development of modern service industries such as online sales, e-commerce, logistics and distribution, the sales channels of the consumer goods industry were not only offline channels, but also various online platforms. Therefore, compared with SARS, the impact of the new crown pneumonia epidemic on the consumer goods industry is relatively small, and the recovery ability is stronger.

\subsection{Manufacturing Industry}

During the "SARS" epidemic in 2003, China's manufacturing industry was in a period of rapid growth and rapid growth due to the wide market after China's entry into the WTO and the relatively low domestic labor costs. The cumulative growth rate of manufacturing inventory during the "SARS" period in 2003 only slightly slowed down. With the end of the epidemic, the growth rate continued to rise rapidly. Therefore, the "SARS" epidemic had a small impact on the manufacturing industry in 2003.

Compared with the 2003 SARS epidemic, when the new crown pneumonia broke out, the international status and development environment of China's manufacturing industry have undergone tremendous changes. In terms of international status, China already has the international status of the "world factory", the manufacturing industry accounts for much higher proportions than other countries, there are many export companies, and it is in a transitional stage. In the development environment, the WHO has classified the new crown pneumonia epidemic as an international public health emergency, which has caused a certain degree of concern in the international market and raised the threshold for Chinese shipments. China's manufacturing industry will face a complex environment such as market demand adjustments, rising factor costs, and restricted product exports [9]. Therefore, the impact of the new crown pneumonia epidemic on the manufacturing industry may be greater than that of the SARS epidemic.

On the other hand, the new crown pneumonia epidemic is also conducive to promoting the informatization transformation of China's manufacturing industry, accelerating the innovation and application of artificial intelligence, 5G technology, and biomedicine, and further enhancing China's ranking and voice in the global value chain.

\subsection{Catering, Hotel, and Tourism Industry}

Reviewing the 2003 SARS period, catering, hotel, and tourism industry have been affected significantly. According to data from the NBS, all the star hotels occupancy growth rate plunged in 2003, from positive $2 \%$ to negative $4 \%$. But in 2004 , there was a "retaliatory" rise of $5 \%$. The overall consumption in the catering industry was also affected in 2003.The growth rate of the catering industry fell from $27.4 \%$ in 2002 to $19.7 \%$ in 2003 but in 2004 the figure increased significantly by $54.4 \%$ [10]. The SARS epidemic has not fundamentally shaken the industrial foundation and development advantages of China's catering, hotel and tourism industries. The market demand for such industries is still strong. At the same time, after the SARS epidemic, the country has issued a series of policies to support the recovery of tourism and other industries that have been affected by SARS. Therefore, the development of the catering, hotel and tourism industries in 2004 showed the characteristics of rapid recovery and strong rebound.

Drawing on the historical experience of fighting the SARS epidemic in 2003, this article can predict that even the new crown pneumonia epidemic may have a shortterm huge impact on the catering, hotel and tourism industries. But once the epidemic is over, the suppressed citizens will form a strong rebound in consumer demand, and the development trend of catering, hotels and tourism will quickly return to the normal growth track.

\subsection{Transportation Industry}

Based on historical experience, the SARS epidemic affected the transportation industry for a long period of about 4 months, and then quickly recovered. Although the speed of recovery of passenger transportation and freight transportation is different, they can all return to normal development levels 3 months after the end of the epidemic. Therefore, this article can predict that the impact of the new crown pneumonia epidemic on the transportation industry will be short-term and will not cause long-term changes in trends.

But on the other hand, the impact of the new crown pneumonia epidemic on the transportation industry will far exceed the SARS epidemic, and it will show the characteristics of "wide impact, deep impact, rapid decline, and long duration". This stems from the relatively severe outbreak of the new crown pneumonia in China in February 2020. All regions initiated the highest-level level I response to major public health emergencies, which was not available during the previous SARS epidemic. On the whole, the impact of this epidemic is wider and deeper. Strict traffic control measures have been adopted everywhere, and personnel travel, 
transportation demand and traffic construction projects have basically stagnated. When the new crown pneumonia epidemic was effectively controlled in the country, it began to pandemic globally, making the related prevention and control work more difficult than the SARS epidemic and showing a trend of normalization.

\subsection{Logistics Industry}

The impact of SARS epidemic on logistics is mainly reflected in four aspects: First, the number of logistics has decreased. In April 2003, the national highway freight volume was 876 million tons, which showed signs of decline from 893 million tons in the previous month and 896 million tons in the same period last year. The second is the change of fluid structure. The sudden SARS epidemic broke the original fluid structure, and the volume of medical supplies, cleaning supplies, fitness supplies, and daily necessities increased abnormally. Third, the logistics speed has slowed down. Due to the implementation of the "self-insurance" policy in various places, freight transport, especially road freight transport, has been severely blocked, and the logistics speed has been greatly reduced. The fourth is the increase in logistics costs. Factors such as slow speeds, increased travel time and other factors, coupled with local blockades and the rise of indiscriminate charges, have prompted a rapid increase in logistics costs.

On the whole, SARS has a negative impact on the logistics industry, but it also has positive effects. For example, logistics information and e-commerce have obtained new development opportunities and promote the rapid development of China's logistics industry. In this new crown pneumonia epidemic, China's mature logistics operation mechanism has the ability to support the nationwide material operation needs, and has played a large role in the supply and deployment of emergency supplies. The logistics industry has become the backbone of the fight against the epidemic.

\subsection{Financial Industry}

\subsubsection{Banking Market}

The impact of SARS on the banking industry in 2003 mainly includes three aspects: first, the scale growth rate will significantly slow down, the profit prospects are not optimistic. Second, the credit risk of the regions and industries severely affected by the epidemic has increased. Third, volatility in financial markets will exacerbate bank liquidity risks.

When COVID-19 does break out, the impact on the banking sector will be mitigated by the following background: First, e-commerce is now well established. The epidemic will mainly affect the industry dominated by offline business. At present, China has a complete industrial chain of e-commerce mode dominated by online business, which can offset the impact caused by the narrowing of offline business to a certain extent. Second, network banking has developed rapidly. The payment and clearing system of many banks has been very developed, and customers can directly realize online payment through various electronic devices and mobile terminals, minimizing the impact caused by the sharp decline of "contact" business. Third, China's commercial banks have stronger risk resistance. In 2003, the reform of the banking industry was still in the beginning stage, the degree of marketization was low, the management ability was weak, and the pressure of asset quality was great. At present, the banking industry has larger assets, significantly improved operating capacity and stronger risk resistance.

\subsubsection{Securities Market}

During the SARS epidemic, China's economy was in the stage of rapid growth and there was a large risk buffer space, so the stock market did not experience violent fluctuations. In 2002, China further opened its stock market to the outside world and officially passed the Qualified Foreign Institutional Investor (QFII) system.

As a result, foreign capital can reasonably enter China's stock market for investment. In addition, steel, petrochemical, automobile, finance, electric power and other sectors led the rise of the index in 2003. Although the SARS epidemic caused periodic adjustment of the stock market, the overall stock market in 2003 was in a positive direction.

As an emergency, the COVID-19 epidemic changed the short-term decision-making of market subjects to some extent and negatively impacted China's real economy in the first quarter, especially tourism, transportation, logistics, consumption and other industries. However, fundamentally speaking, the longterm factors that determine the long-term positive trend of China's financial market have not changed. First, the long-term positive trend of the overall macro economy has not changed. Second, the basic pattern of the reform and opening up of the financial market has not been shaken. Third, the trend of foreign capital allocation of RMB assets has not changed. In addition, the People's Bank of China and several ministries jointly introduced policies and measures. Under the COVID-19 epidemic, the impact of the Chinese securities market was limited and the recovery was rapid.

\subsection{Foreign Trade Industry}

The impact of this COVID-19 outbreak on foreign trade may be higher than that of the SARS outbreak in 2003. In 2001, China just joined the WTO, and China's economy is developing in a positive direction with huge potential. China's huge consumer market and 
demographic dividend are good for China's foreign trade. Now, however, China's foreign trade situation is more complex, China's foreign trade sustained growth is a major challenge. Nowadays, international trade protectionism is adopted by many countries, and domestic supremacy prevails.

\section{CONCLUSION}

From a historical and macroeconomic perspective, the most comparable case for the economic impact of COVID-19 is SARS in 2003. There are many similarities between the impact of COVID-19 epidemic and SARS epidemic on the economy. However, by sorting out and reviewing the differences in China's economic background, industrial structure and development stage during the SARS epidemic and COVID-19 epidemic, this paper finds that the two epidemics have different impacts and influences on various industries of the economy. Therefore, in order to properly deal with the economic crisis caused by the outbreak, targeted policies must be adopted based on the specific background and national conditions of the outbreak.

\section{REFERENCES}

[1] A.C. Worthington, The Impact of Natural Events and Disasters on the Australian Stock Market: A GARCH-M Analysis of Storms, Floods, Cyclones, Earthquakes and Bushfires, Global Business and Economics Review. 10(2008)1.

[2] C. Goh, R. Law, Modeling and Forecasting Tourism Demand for Arrivals with Stochastic Nonstationary Seasonality andIntervention, Tourism management. 23(2002)499-510.

[3] T. Deryugina, L. Kawano, S. Levitt, The Economic Impact of Hurricane Katrina on its Victims: Evidence from Individu-al Tax Returns, American Economic Jounal: Applied Economics. 10(2018)202-233.

[4] C.E. Boehm, A. Flaaen, N. Pandalai-Nayar, Input Linkages and the Transmission of Shocks: Firmlevel Evidence fromthe 2011 Tōhoku Earthquake, Review of Economics and Statistics. 101(2019)6075 .

[5] H. White, T.H. Kim, S. Manganelli, VAR for VaR: Measuring Tail Dependence Using Multivariate Regression Quan-tiles, Journal of Econometrics. 187(2015)169-188.

[6] M.A. Lasfer, A. Melnik, D.C. Thomas, Short-term Reaction of Stock Markets in Stressful Circumstances, Journal of Banking and Finance. 27(2003), 1959-1977.
[7] M. Marcellino, V. Sivec, Monetary, Fiscal and Oil Shocks: Evidence Based on Mixed Frequency Structural FAVARs, Journal of Econometrics. 193(2016)335-348.

[8] X.M. Liu, Z.G. Han, A Evaluating Model of Impact on Some Economic Targets Which Caused by SARS. College Mathematics. 21(2005)15-17.

[9] X.J. Meng, A Series of Reports on focusing heat point of Bond Market: Analyze the Epidemic's Impact Through Labour-Intensity Degrees of Industries. Shanghai: Shenwan Hongyuan Securities. (2020)17.

[10] L. Mei, Analysis of the Impact of COVID-19 on Catering and Tourism Industry: Review and Analyze How the Catering and Tourism Sectors Perform Under the Epidemic. Shanghai: China Merchants Securities. (2020)4-16. 